DOI 10.37882/2223-2982.2020.10.10

\title{
КОГНИТИВНОЕ МОДЕЛИРОВАНИЕ ЖАНРОВ МАССОВОЙ ЛИТЕРАТУРЫ (НА ПРИМЕРЕ АНГЛОЯЗЫЧНЫХ ДЕТЕКТИВНЫХ ПРОИЗВЕДЕНИЙ)
}

\section{COGNITIVE MODELING OF GENRES OF MASS LITERATURE (ON THE EXAMPLE OF ENGLISH-LANGUAGE DETECTIVE STORIES) \\ T. Vatolina}

Summary: This article examines one of the most socially significant and popular genres of mass literature - detective discourse, the artistic world of which is generated and functions around an invariant cognitive model, which is an integral cognitive structure abstracted from classical Englishlanguage detective stories.

Keywords: detective discourse, cognitive contour, cognitive model, conceptual system, character, role-playing nomination, artistic world.
K огнитивное моделирование представляет один из видов анализа, направленный на определение вектора применения силы с учетом влияния самых различных факторов на объект воздействия. В данном случае объектом воздействия является именно читатель. Сегодня моделирование стало составной частью любого научного исследования, модели для изучения создаются в самых разных научных областях, без когнитивного моделирования невозможны изучения любых лингвистических явлений, а также процессы, их рождающие и направленные на восприятие всех возможных видов дискурса. Именно когнитивное моделирование предназначено для наиболее точного анализа сути изучаемого явления.

Поэтому на примере англоязычных детективных произведений проведем анализ когнитивного моделирования жанров массовой литературы.

Считается, что детективный жанр является особенным жанром, который длительное время не подвергался серьезной критике исходя из того, что не каждый читатель мог понимать правильно и логично происходящее на страницах детектива, не все могли поделиться грамотным восприятием классиков детективного жанра. Другими словами, не всем давался детективный жанр англоязычных произведений, особенно после перевода, так как для понимания происходящего на страницах необходимы были определенные знания географического, исторического, социального и другого характера, которые у большинства читателей, допустим СССР или Рос-

\author{
Ватолина Татьяна Геннадьевна \\ К.филол.н., старший преподаватель, Крымский \\ инженерно-педагогический университет \\ имени Февзи Якубова \\ bianka80@mail.ru
}

Аннотация: В данной статье рассматривается один из самых социально значимых и востребованных жанров массовой литературы - детективный дискурс, художественный мир которого генерируется и функционирует вокруг инвариантной когнитивной модели, представляющей собой абстрагированную из англоязычных классических детективных произведений целостную когнитивную структуру.

Ключевые слова: детективный дискурс, когнитивный контур, когнитивная модель, концептуальная система, персонаж, ролевая номинация, художественный мир.

сии, просто отсутствовали. Это в настоящее время создаются так называемые бульварные детективы широкого доступа и детективные жанры на любой вкус, предназначенные только для бесцельного времяпровождения и не требующие никаких особенных знаний.

Тем не менее, анализируя англоязычные произведения детективного жанра, нельзя не назвать хорошо известные всему миру имена А.К. Дойля, Э.А. По, А. Кристи, Г.К. Честертона, Д. Сайерс, Э. Гарднера и других великих мастеров.

Считая детективный жанр не совсем серьезной литературой, в России в настоящее время отсутствует его глубокий анализ, существуют обзорные статьи Г.А. Анджапаридзе, А.Г. Адамова, А.З. Вулиса, Я.К. Маркулан и некоторых других ученых, например, И.А. Дудина дала оценку особенностям развития и действиям определенных составляющих детективного дискурса [Дудина, 2008], Н.Ю. Филистовой проведен некоторый сопоставительный анализ когнитивных особенностей и семантики русского и английского языков, Э.В. Калашниковым изучены англоязычные детективы как категории текста и его особенности. Этого, конечно, очень мало и недостаточно, еще не изучены когнитивно-дискурсивные параметры исследуемого нами детективного жанра, отсутствует систематизация его параметров - это очень большая и трудоемкая работа.

Однако, на наш взгляд, любая массовая литература должна подвергаться изучению и анализу, хотя бы пре- 
следуя любую возможность запретительных мер для низкопробного бульварного чтива, которое не несет никакой смысловой нагрузки. Но в одном солидарны и зарубежные, и отечественные исследователи этого жанра - детективный дискурс является социальным феноменом, который всегда реагирует на политические и экономические изменения в обществе, он является массовым жанром и всегда более востребован, в отличие от других жанров литературы, именно поэтому его более детальное исследование должно быть продолжено.

Структура изучаемых нами произведений представляет собой очень сложную систему, в состав которой входят несколько взаимосвязанных друг с другом контуров взаимодействия. Если отдельно рассмотреть когнитивную структуру художественного мира классического детектива, то в каждом из них эти контуры обеспечивают постепенное управляемое развитие событий в определенных сценарием рамках, присущие практически любому стандарту существующего жанра любого детектива «Убийство» - «Расследование» - «Объяснение», а также сопутствующие жанру действия и определенную, последовательную деятельность действующих лиц. Одновременно с этим, если отдельно изучать эти когнитивные контуры, представляющие собой системный постоянный сегмент, присущий определенной структуре созданных автором определенных и необходимых составляющих, цепочке событий, являющейся постоянной и неизменной на протяжении всего сценария произведения. Совокупность этих контуров представляет собой жанрообразующую когнитивную модель, на основе которой детективные произведения на глубинном уровне порождаются и функционируют, а на поверхностном уровне данная модель актуализируется в языковых знаках каждого конкретного детективного произведения, сигнализируя читателям, с каким именно жанром массовой литературы они имеют дело, обеспечивая узнаваемость и востребованность детективного дискурса в целом.

Необходимо четко представлять себе, что любое англоязычное произведение детективной направленности - это самостоятельный и разнообразный художественный мир, он не возникает сам по себе, а строится по определенному сценарию автора - по хорошо продуманной определенной схеме, которая присуща всем детективным произведениям.

Этому сценарию присущи некоторые теоретические принципы когнитивного моделирования, основанные на современном языковедении:

- Синтез отдельных информационных кластеров в виде самостоятельных и целенаправленных когнитивных структур (значений, смыслов, когнитивных сценариев), которые в пределах детективного жанра всегда неизменны и постоянны при изме- нении только языковых величин;

- Объединение целенаправленных когнитивных структур в виде блоков по схожим признакам и их одновременного абстрагирования;

- Нахождение связей и взаимоотношений между объединенными блоками и структурами, установление условий их функционирования.

А когнитивное моделирование детективного дискурса содержит несколько взаимосвязанных друг с другом структур взаимного функционирования, а когнитивные структуры, в свою очередь, группы блоков определенных знаний, присущих данному жанру. Они были абстрагированы на основе когнитивного моделирования языковых величин.

Абстрагирование и объединение произведено нами с момента установки общих ролевых названий действующих лиц детективного дискурса, входящих в первую структуру взаимного функционирования общей когнитивной модели детективного дискурса.

Говоря об обобщенных чертах для всех действующих лиц в детективном жанре необходимо остановиться на разработках Ю. Кристевой, которая методом структурного анализа текста художественного произведения выявила общие черты для всех действующих персонажей. Совершенствуя работу В.Я. Проппа о понятии «класса персонажей», Ю. Кристева ввела новое определение «актант», который в отличие от персонажа в пределах какого-то одного художественного произведения, является обобщенным персонажем для многих произведений с присущими только ему определенными действиями. Теперь становится проще рассуждать о строении художественных произведений и месте персонажей в них: если действующие лица и персонажи создают отдельное произведение, то определенный набор актантов создают целый жанр в художественной литературе. Отличительным признаком актантов по отношению к действующим лицам и персонажам является обладание ими метаязыкового статуса. Выделение в жанре произведения актанта происходит через «дискурс, который он себе присваивает и посредством которого обозначается в романе» [Пропп, 2003; Кристева, 2004].

Если использовать разработанные Ю. Кристевой алгоритмы абстрагирования актантов на основе дискурса, с помощью которого они обозначаются в детективном жанре, то сам детективный жанр предстает перед нами очень простым и несложным с точки зрения построения его структуры персонажей и действующих лиц, то есть при всем разнообразии персонажей количество актантов в нем весьма ограничено, а в любом детективе мы не сможем найти актантную множественность по отношению к одному и тому же действующему лицу. 
Объединение единообразных номинаций в группы и выделение из каждой группы общей и ничем не примечательной номинации (detective, private detective, consulting detective, amateur of crime, resolver of mysteries, unraveller of knots, private sleuth, watchdog $\rightarrow$ detective; murderer, criminal, maniac $\rightarrow$ murderer; friend, associate, assistant, companion, emissary, representative $\rightarrow$ assistant; witness $\rightarrow$ witness; victim, body, dead woman/man, corpse, poor old soul/guy $\rightarrow$ victim), дает нам возможность доказать, что практически в каждом детективном произведении англоязычного происхождения легко определяются всегда пять типов действующих лиц, которые предлагаем обозначать используя абстрагированные номинации: ДЕТЕКТИВ, УБИЙЦА, ПОМОЩНИК, СВИДЕТЕЛЬ, ЖЕРТВА. Эти номинации являются названиями определенных значений, определяющими всегда только личностную идентификацию для конкретного художественного жанра, а на уровне актантно-персонажной структуры используются определенные знания, представляющие всех персонажей абсолютно идентичными и похожими с точки зрения их когнитивной функции.

Представление единой номинации идентичности, например такой, как ДЕТЕКТИВ, на уровне когнитивного моделирования может служить абстрагированным именем собственным, заменяющим все конкретные имена персонажей жанра (Father Brown, Sherlock Holmes, Miss Marple, Hercule Poirot, Albert Campion и другие). Bcex их можно обозначить как ДЕТЕКТИВ, поэтому логично будет писать исследуемые номинации заглавными буквами.

Следующей когнитивной структурой созданной нами модели является концептуальная структура, в которую входят группы идентичности действующих лиц, то есть предыдущая структура, а также исследуемое нами значение общего концептуального стандарта детективного жанра, включающего в себя единую систему «Убийство» - «Расследование» - «Объяснение». С.Н. Плотникова ввела термин концептуального стандарта, понимая под ним инвариантную концептуальную систему, наличие которой в произведении является обязательным условием причисления текста к какому-либо определенному жанру. О наличии концептуального стандарта произведения по С.Н. Плотниковой можно выделить следующие положения:

- Существование большого количества художественных произведений или текстов, написанных по «шаблону» того или иного жанра;

- Любой читатель на бессознательном уровне всегда достаточно точно определяет жанр произведения, что свидетельствует о владении интуитивным знанием об концептуальном стандарте жанра [Плотникова, 2005].

С. Н. Плотникова также считает, что определение концептуального стандарта детективного жанра является очень простым и не сложным по сравнению с определениями, например, жанра фэнтези и других, более сложных жанров [Плотникова, 2005]. Именно поэтому систему «Убийство» - «Расследование» - «Объяснение» можно считать концептуальным стандартом жанра.

Но в нашем исследовании впервые выделено два основных типа дискурса, динамично переходящих друг в друга в соответствии с концептуальным построением произведения детективного жанра. При продвижении повествования и развития событий элемент «Расследование» переходит в элемент «Объяснение», причем особенно выделяется дискурс расследования, его можно назвать дискурсом «вопрошания» мира, отнесенный полностью в ведение ДЕТЕКТИВА, завершением детективного произведения является дискурс объяснения. А элемент «Убийство» рассматривается в дискурсе «вопрошания» и объяснения, то есть этот первый элемент структуры детективного дискурса является еще главным в теме произведения.

Сценарная когнитивная система созданной нами когнитивной модели детективного дискурса является следующим последовательным понятием, выделенным нами в ходе когнитивного моделирования детективного жанра. Это понятие воплощается в цепочке речевых действий или речевых актах концептуальных персонажей, где центральным является ДЕТЕКТИВ и время его появления на страницах произведения считается началом его наблюдения за художественным миром. Реализация всей когнитивной деятельности на данном уровне осуществляется в сообщении об убийстве и в дальнейшем «вопрошании» ДЕТЕКТИВОМ всех остальных действующих лиц произведения по поводу убийства. Все же речевые акты ДЕТЕКТИВА на этом уровне когнитивной модели являются только шаблонами и директивами. Как, например, происходит в рассказе А. Кристи «The Adventure of the Egyptian Tomb»:

(Poirot): Now, let us come to facts, that I may have guidance. Your husband had always been a devoted egyptologist, hadn't he?

(Lady Willard): Yes, from his youth upwards. He was one of the greatest authorities upon the subject.

(Poirot): But Mr. Bleibner, I understand, was more or less of an amateur?

(Lady Willard): Oh, quite, he was a very wealthy man who dabbled freely in any subject that happened to take his fancy. My husband managed to interest him in Egyptology, and it was his money that was so useful in financing the expedition.

(Poirot): And the nephew? What do you know of his tastes? Was he with the party at all?;

(Poirot): When did Mr. Schneider's death take place?

(Ames): Three days ago. 


\section{(Poirot): You are sure it was tetanus?}

(Ames): Dead sure.

(Poirot): It couldn't have been a case of strychnine poisoning, for instance?

(Ames): No, Monsieur Poirot, it was a clear case of tetanus. (Poirot): Did you not inject anti-serum?

(Ames): Certainly we did.

Здесь, как и в других подобных диалогах, мы имеем однотипный дискурс. Всегда спрашивает только ДЕТЕКТИВ, остальные персонажи вынуждены отвечать, поэтому диалоги из детективных произведений нельзя назвать естественными, но можно признать их вынужденными. Ведь все подвергнуты коммуникативному давлению ДЕТЕКТИВА и вынуждены ему подчиняться, даже УБИЙЦА, когда он будет задержан или идентифицирован как убийца, вынужден признавать над собой власть ДЕТЕКТИВА. Все это лишь подтверждает выводы С.Н. Плотниковой о том, что действующие лица детективного дискурса всегда не миметические (не подражательные), а концептуальные. Это говорит о том, что художественный мир детективного жанра всегда более удален от реального мира по сравнению с подражательными мирами, создаваемыми в реалистической литературе [Плотникова, 2006].

Элемент «Объяснение» в нашем случае является отдельной частью художественного мира детективного жанра, которая всегда заканчивает произведение. С точки зрения лингвистики «Объяснение» устроено по образу аргументативного дискурса, потому что всегда воплощается в использовании присущих только ему языковых образований. Именно эта очевидность наблюдается во всех произведениях детективного жанра на их заключительных стадиях.

Следующим понятием когнитивной структуры является элемент общей системы художественного мира и естественное разделение этого мира на две половины: невидимую (истинную) и видимую (ложную). Разделение понятий динамики картин мира от ложной к истинной и наоборот предоставляет нам очевидную возможность соединения двух противоположных когнитивных структур в одну общую модель детективного дискурса: действительный и кажущийся миры. Т.И. Семенова утверждает, что кажимость является одним из инструментов создания полифонии в дискурсе, двуплановости репрезентируемого в дискурсе мира [Семёнова, 2007]. Объектное пространство детективного дискурса можно разделить на настоящее (подлинное) и симулятивное (вымышленное). Симулятивное в данном случае по $Ж$. Бодрийяру понимается как знак, значение которого симулируется, отрываясь от подлинного [Бодрийяр, 2000]. Поэтому в связи с разделением событий на подлинные и вымышленные, действующие лица произведения де- лятся на когнитивно-компетентного (ДЕТЕКТИВ) и когнитивно-некомпетентных (остальные персонажи). В качестве примера можно привести многие, хорошо известные всем, повести А. Конан-Дойла со знаменитыми персонажами Шерлоком Холмсом и инспектором Лестрейдом. В этих произведениях как весь дискурс расследования, так и объяснения, основан на подробном объяснении истинного соотношения знаков подлинных и вымышленных. ДЕТЕКТИВ (Шерлок Холмс) находится в истинном, правдивом мире логики и фактов, персонаж (инспектор Лестрейд), играющий роль основного детектива по сюжету и сценарию, всегда находится в ложном, вымышленном мире. Соотношение этих двух миров ясно представляют сценарий А. Конан-Дойла о кажимости мира в дискурсе когнитивно-некомпетентных персонажей (инспектор Лестрейд) и выведении ложной картины мира в зону видимости и фактов в дискурсе когнитивно-компетентного персонажа (ДЕТЕКТИВА Шерлока Холмса). Например, в повести «A Study in Scarlet» полицейский инспектор Лестрейд выступает в роли ПОМОЩНИКА и представляет собой некомпетентного персонажа, соотнося надпись на стене Rache с именем Rachel. ДЕТЕКТИВ (Шерлок Холмс) путем логических умозаключений и с помощью обычной внимательности восстанавливает взаимосвязь знаков, отражающую взаимодействие элементов, меняет уводящий в сторону симуляции знак Rachel на правильный по сценарию revenge, то есть восстанавливает истинное значение знака. Такими примерами полны все основные произведения А. Конан-Дойла, связанные с ДЕТЕКТИВОМ (Шерлоком Холмсом) и ПОМОЩНИКОМ (инспектором Лестрейдом).

Таким образом, в данном исследовании произведен анализ общих для детективного жанра англоязычных произведений признаков, что позволило предоставить ряд фактических доказательств, показывающих завершенную и неизменную конструкцию на сценарном уровне любого англоязычного произведения детективного жанра, состоящего из взаимосвязанных элементов когнитивных структур, а каждая когнитивная структура - это система постоянных и неизменных сущностных величин и художественных знаний, находящаяся в завершенном и неизменном состоянии.

А когнитивное моделирование детективного дискурса представляет собой когнитивное единство, состоящее из конкретных детективных произведений, на основе которых оно рождается и работает. В данной статье показано, что на глубинной сценарной ступени когнитивное моделирование приводит произведения к однообразию и простоте сущности детективного жанра, но на практической ступени, формируясь в языковых знаках конкретных произведений, в области массовой литературы обеспечивает его узнавание, продвижение и спрос. 


\section{ЛИТЕРАТУРА}

1. Бодрийяр, Ж. Символический обмен и смерть / Ж. Бодрийяр. - М.: «Добросвет», 2000. - 387 с.

2. Ватолина Т.Г. Когнитивная модель детективного дискурса (на материале англоязычных детективных произведений XIX-XX вв.): дис. ... канд. филол. наук: 10.02.04 / Т.Г. Ватолина. - Иркутск: ИГЛУ, 2011. - 209 с.

3. Дудина, И.А. Дискурсивное пространство детективного текста: на материале англоязычной художественной литературы XIX-XX вB. Текст.: дис. канд. филол. наук: 10.02.19 / И.А. Дудина. Краснодар: Кубанский гос. ун-т, 2008.-259 с.

4. К Кристева, Ю. Избранные труды: Разрушение поэтики [Текст] / Ю. Кристева. - М.: «РОССПЭН», 2004. - 656 с.

5. Пропп, В.Я. Морфология сказки [Текст] / В.Я. Пропп. - М.: Изд-во Лабиринт, 2003. - 144 с.

6. Плотникова, С.Н. Концептуальный стандарт жанра фэнтези [Текст] /С.Н. Плотникова // Жанры речи: Сборник научных статей. - Саратов: Изд-во Гос УН-Ц, 2005. Вып. 4. Жанр и концепт. - С. $262-272$.

7. Плотникова, С.Н. Человек и персонаж: Феноменологический подход кестественной и художественной коммуникации [Текст] / С.Н. Плотникова // Человек в коммуникации: концепт, жанр, дискурс. - Волгоград: Парадигма, 2006. - С. 89-104.

8. Семёнова, Т.И. Лингвистический феномен кажимости [Текст]: монография / Т.И. Семёнова. - Иркутск: ИгЛу, 2007. - 237 с.

( ) Ватолина Татьяна Геннадьевна (bianka80@mail.ru).

Журнал «Современная наука: актуальные проблемы теории и практики»

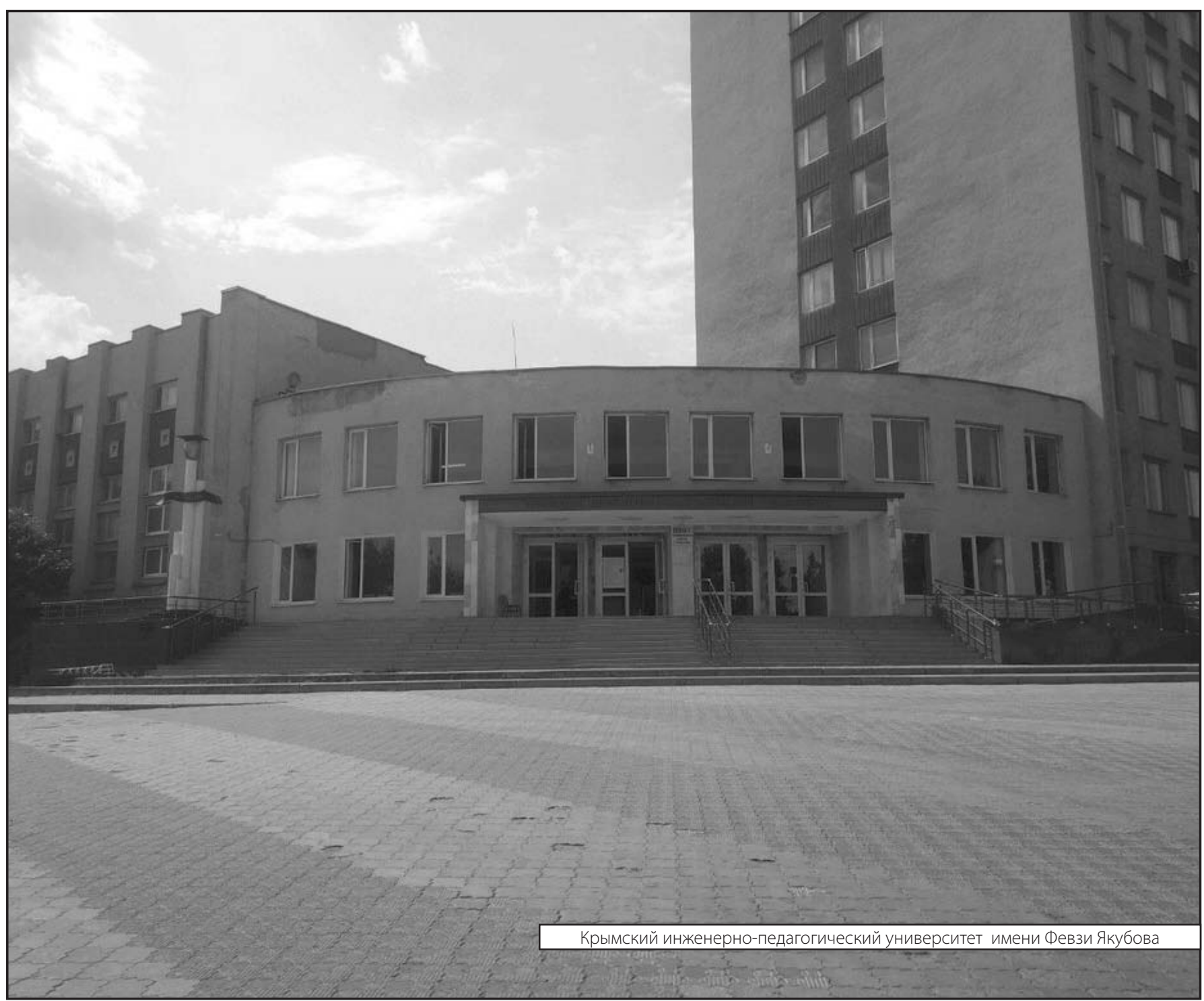

